Turk Med Stud J 2022;9(1):14-9

REVIEW

DOI: $10.4274 /$ tmsj.galenos.2022.09.01.03

\title{
EFFECTS OF MALNUTRITION ON THE PROGNOSIS OF PEDIATRIC ACUTE LYMPHOBLASTIC LEUKEMIA PATIENTS
}

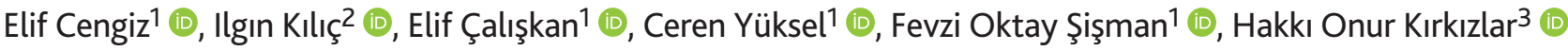 \\ ${ }^{1}$ Trakya University School of Medicine, Edirne, TURKEY \\ 2University of Liverpool School of Medicine, Liverpool, ENGLAND \\ ${ }^{3}$ Trakya University School of Medicine, Department of Internal Medicine, Division of Hematology, Edirne, TURKEY
}

\section{ABSTRACT}

Acute lymphoblastic leukemia is the most common cancer among children and adolescents, with a rate of $34 \%$ of all cancers in this population. Studies have been conducted to question the relationship between the prognosis and nutritional status of pediatric acute lymphoblastic leukemia patients. Malnutrition refers to inadequate nourishment and obesity. Both ends of the spectrum of nutritional status might have implications on the prognoses. This review aims to illustrate the relationship between malnutrition and the acute lymphoblastic leukemia prognosis, and to address the bone health of the patients.

Keywords: Lymphoblastic leukemia, malnutrition, osteonecrosis

\section{INTRODUCTION}

Acute lymphoblastic leukemia (ALL) is the most common cancer among children and adolescents, with a rate of $34 \%$ of all cancers in this population $(1,2)$. ALL is a malignant transformation and proliferation of lymphoid progenitor cells (3). Chromosomal abnormalities and genetic changes are the prognostic indicators of the disease (3). The incidence of ALL in children between newborn and 14 years of age is $3-4 / 100,000$ and $1 / 100,000$ in patients older than 15 years (2). The peak incidence age for ALL is 2 to 5 years of age (2). The clinical manifestation of ALL is the accumulation of poorly differentiated lymphoid cells in the bone marrow, peripheral blood, and extramedullary regions (3).

Dose-intensification strategies have improved the prognostic outcome in children between 1-14 years with ALL (4).

There have been studies that question the relevance of nutritional status on pediatric ALL patients' prognoses. The term 'malnutrition' generally connotes inadequate nourishment, although, in clinical practice, it also refers to obesity (5). Both ends of the spectrum of nutritional status, under and over-nutrition, may have consequences on the prognoses. In this review, we aim to illustrate the relationship between malnutrition and the course of ALL.

Diagnosis of malnutrition is mainly based on standard anthropometric indices such as height-for-age or length-forage Z-score and weight-for-length Z-score, mid-upper arm circumference (MUAC), and edema (6). If a child aged 6-59 months has at least one of either weight-for-height Z-score $<-2$, MUAC $<125 \mathrm{~mm}$ or the presence of nutritional edema, he/she can be diagnosed with acute malnutrition (6). Another research aiming to provide consensus-based criteria for the diagnosis of malnutrition suggests two options (7). The first of these options is having a body mass index (BMI) lower than $18.5 \mathrm{~kg} / \mathrm{m}^{2}$, and the second one is having unintentional weight loss and at least one of either low fat-free mass index or reduced BMI $\left(<18.5 \mathrm{~kg} / \mathrm{m}^{2}\right)(7)$.

Address for Correspondence: Elif Cengiz, Trakya University School of Medicine, Edirne, TURKEY

e-mail: elifcen@gmail.com

ORCID iDs of the authors: EC: 0000-0002-5902-2904; IK: 0000-0001-7393-7839; EÇ: 0000-0003-4556-8698;

CY: 0000-0003-2456-7282; FOŞ: 0000-0002-9942-9418; HOK: 0000-0001-7523-8599.

Received: 05.01.2022 Accepted: 19.01.2022

Cite this article as: Cengiz E, Kılıç I, Çalışkan E et al. Effects of malnutrition on the prognosis of pediatric acute lymphoblastic leukemia patients. Turk Med Stud J 2022;9(1):14-9.

Copyright@Author(s) - Available online at https://www.turkmedstudj.com/ 


\section{Symptoms of Acute Lymphoblastic Leukemia}

Acute lymphoblastic leukemia usually has a variety of nonspecific symptoms (8). Fever caused by leukemia or a secondary infection due to neutropenia is one of these symptoms (2). Shortness of breath due to mediastinum enlargement, bone and joint pain, swelling of lymph nodes, fatigue and lethargy caused by anemia, petechiae and bleeding diathesis connected to thrombocytopenia are also different symptoms of $\operatorname{ALL}(2,8)$.

\section{Relevance of Malnutrition with Clinical Outcomes for Patients with Acute Lymphoblastic Leukemia}

Eighty-five percent of all children reside in developing countries, and the well-being of the community is adversely affected by the lack of accessibility to health care, presence of infectious diseases, or undernourishment (9). In developing countries, the prevalence of malnourishment in children under five years old is thought to be between $20 \%$ and $71 \%$ with an estimate of $43 \%$ (9). It is assumed that malnutrition is prevalent in $50 \%$ of pediatric cancer patients at diagnosis in the developing world, and in less than $10 \%$ in industrialized countries for ALL patients, which rises to $50 \%$ for patients with advanced neuroblastoma (9). Despite its value, data relevant to the nutritional aspect of cancer patients' presentations is lacking, especially in developing countries.

Evaluating the nutritional status of patients with malignancies at the time of diagnosis and tracking it during treatment is crucial due to its potential effect on disease progression and course of survival (9).

\section{Nutritional Morbidity at Diagnosis}

In a study conducted with 105 Mexican ALL patients, no evidence of malnutrition was found, as measured by measurements of MUAC and triceps skinfold thickness (TSFT) for three months (10). Another Italian study compared 173 children, newly diagnosed with ALL, to 307 children with non-malignant diseases in terms of anthropometric measures; MUAC and TSFT (11). No statistically significant difference was observed $(p=0.077)$. Studies conducted in Casablanca and Guatemala revealed $20-50 \%$ of child patients who were being treated for cancer were malnourished (12, 13). However, a study ran in Northern Mexico pointed out that most pediatric ALL patients were well nourished when diagnosed (14). Another study, by Children's Cancer Group, that concentrated on obesity presentation in accordance with the patients' BMI assessed over 4,000 children and youths with ALL (15). They observed that the event-free survival rate for 5-years was worse in obese patients, with a higher possibility of relapse in patients at and over 10 years of age (15).
Due to these contradictory findings, the presence and prevalence of malnutrition at diagnosing ALL are inconclusive. However, most studies indicate that malnutrition may not be a prevalent problem at the time of $\operatorname{ALL}$ diagnosis $(12,14)$. The need for further assessment to determine the patients' risk of nutritional morbidity perseveres $(12,13)$.

\section{Nutritional Morbidity During Treatment}

Some researchers believe malnourished patients have decreased tolerance to chemotherapy, altered metabolism for antineoplastic drugs, reduced immunity, are more prone to acquiring more persistent and common infections, and present a higher rate of therapy failure $(16,17)$.

Lobato-Mendizábal et al. (16) reported that malnourished children had a worse 5-year event-free survival rate $(26 \%)$ than well-nourished children (83\%). They also reported malnourished children had lower cumulative doses of maintenance chemotherapy and had more recurrences (16).

Another group reported that malnourished children, based on weight-for-height analysis, had a significantly higher risk of death in earlier phases of treatment compared to their well-nourished counterparts, the study also concluded that malnourished children were 3.5 times more likely to die during maintenance chemotherapy (17).

Cancer treatment may deepen nutrient deficiencies and cause nutritional morbidity, which shows a necessity for nutritional intervention $(16,17)$.

\section{Nutritional Status and Appetite-regulating Hormones in the Early Treatment of Acute Lymphoblastic Leukemia}

The treatment of ALL aims to achieve normal hematopoiesis, to prevent resistant subclone formation and disease progression to other sites in the body, and to prevent relapse (10). Several treatment modalities differ from each other with the drugs involved in the protocol, but the main object of the treatment protocols depends on a basic strategy (10). Induction, consolidation, and maintenance is the most common three-phase treatment plan. Induction therapy aims to re-establish normal blood cell synthesis (10). The consolidation stage involves using agents to eradicate residual abnormal blood cells (10). These two stages can be considered as early treatment, whereas maintenance therapy aims to prevent relapse (18). Figure 1 shows common agents used in the three-phase treatment processes (8).

In addition to these therapeutic agents, environmental factors like diet and adequate nourishment are crucial for ALL treatment, especially during the early treatment stages since inadequate nutrition can decrease patients' tolerance to chemotherapy and cause reduced immunity, which increases susceptibility to infections and reduces survival 


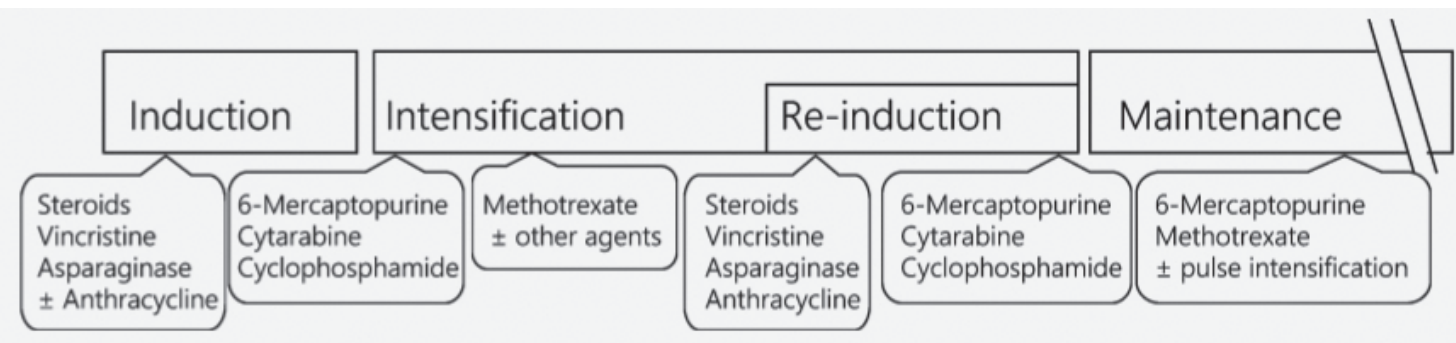

Figure 1: Treatment plan for pediatric acute lymphoblastic leukemia, taken from Kato and Manabe (8).

(19). In addition to this, dietary intake is known to contribute to ALL patients' bone health and mass, and certain dietary changes can contribute to the treatment-related toxicity in ALL patients (20).

Food intake is regulated by appetite-regulating hormones such as ghrelin, leptin, insulin, glucagon, and cortisol (21). However, appetite-regulating mechanisms are more complex in pediatric cancer patients (21). Increases and decreases in these hormones can manifest themselves with either weight gain or weight loss during and after ALL treatment, causing patients to be overweight or underweight, both affecting disease progression (21). However, there is no direct correlation between food intake and body composure in pediatric ALL patients, showing the complexity of the energy balance mechanisms involved in cancer (21). This complexity shows that there is a need for early intervention in the dietary status of ALL patients during early treatment stages to decrease the risk of nutritional complications (21).

It is common for newly diagnosed ALL patients to present in an underweight anorexic-cachectic state or an overweight state (22). For example, Brinksma et al. (22) showed that many newly diagnosed ALL patients had lower than predicted Z-scores in growth curves; whereas Ladas et al. (20) showed that $27 \%$ of newly diagnosed ALL patients were obese prior to treatment. Similarly, Gomes et al. (21) and Tan et al. (23) showed the percentage to be $21.4 \%$ and $24.5 \%$, respectively. In addition, Lindemulder et al. (24) reported that many newly diagnosed pediatric ALL patients' BMIs statistically significantly increased between induction and consolidation treatments.

Studies showed varying results regarding levels of appetite hormones during treatment for ALL. Gomes et al. (21) showed a slight increase in ghrelin levels with no significant change in leptin levels. Park et al. (25) showed decreased leptin levels in pediatric cancer patients compared with healthy patients, whereas Moschovi et al. (26) showed no significant change in leptin levels throughout early treatment. Fasting insulin levels in the study conducted by Esbenshade et al. (27) showed a statistically significant increase during the first year of treatment, including maintenance therapy.
A better understanding of the complex appetite regulation mechanisms in the presence of cancer can lead to the development of more complex therapies for the disease progression of ALL and a better quality of life for ALL patients.

On the other hand, ALL is not the sole malignancy that may cause malnourishment in children (28). In patients with solid tumors, two studies reported the prevalence rate of malnutrition at diagnosis for neuroblastoma to be around $50 \%(28,29)$. One study marked a decrease of $33 \%$ in malnutrition in neuroblastoma patients during treatment and $20 \%$ after the excision of the tumor (28). Another study reported a $31 \%$ malnourishment rate for patients with brain cancer which are medulloblastoma and supratentorial primitive neuroectodermal tumors (30).

These results indicate that malnutrition is a common problem for many childhood cancers along with ALL, and should be handled with care in order to improve the nutritional status of the patients and their quality of life.

\section{The Importance of Malnutrition on Acute Lymphoblastic Leukemia and Bone Health}

Musculoskeletal system deformities are frequently observed in children and adolescents with ALL as the disease and its treatment itself have many adverse effects on musculoskeletal health (31-33). Over the last few decades, the cure rate of ALL approached $90 \%$, therefore minimizing the short-term and long-term side effects of ALL and the intensive treatment protocols for ALL on patients' physical functions gained importance $(32,34,35)$. Reduced bone turnover, bone mineral density (BMD), bone formation, musculoskeletal pain, in addition to abnormalities in gait, fractures due to osteoporosis, and osteonecrosis (ON) have been reported at diagnosis and during treatment of $\operatorname{ALL}(32,34,36-38)$.

\section{Bone Mineral Density and Body Composition}

BMD increases until the early thirties in healthy people, but patients with ALL tend to have decreased BMD due to the disease, its treatment, lack of physical activity, and insufficient nutrition (33). Glucocorticoids, especially dexamethasone, have a major role in treating ALL in children as it promotes lysis of leukemic cells; however, it also reduces bone formation 
by inducing apoptosis of osteoblasts and osteocytes $(32,39)$. Low BMD in childhood may ensue osteoporotic fractures later in life (39). Research by Alos et al. (40) revealed that $16 \%$ of children with ALL had vertebral fractures one year after beginning ALL treatment. The leukemic process has also been linked with low bone turnover as the leukemic cells secrete osteoblast-inhibiting factors and parathyroid hormone-related peptides (39).

In an effort to minimize the effect of low BMD in ALL survivors later in life, patients are often provided nutritional counseling and supplementation, such as vitamin D and calcium. A study conducted by Kaste et al. (41) showed that these treatments did not significantly remediate the low BMD over a two-year period.

Unfortunately, few studies have been conducted on the effects of nutritional deficiencies on bone health in ALL patients and survivors. However, one study suggests that it is possible to prevent the bone health complications of ALL treatment when the patient follows a nutrient-dense diet (42).

\section{Osteonecrosis}

Osteonecrosis is one of the most common and significant sequelae of ALL treatment, causing serious pain, decreased mobility, and joint collapse and therefore reduces long-term survivors' life quality (43). Previous studies show various results on the prevalence (1.6-17.6\%) and risk factors of ON presentation during or after the antileukemic treatment (41). A study conducted by Mattano et al. (44) between 1989 and 1995 revealed $9.3 \%$ of 1,409 children with ALL experienced ON within 3 years after diagnosis. Another study reported the prevalence of ON observed in patients undergoing intensive chemotherapy for ALL as $1.6 \%$ (45). These different outcomes may stem from different types (dexamethasone, prednisone) or dosages of glucocorticoids, adolescent age at diagnosis, or radiation exposure (46). Kadan-Lottick et al. (46) also confirmed that patients treated with dexamethasone were $30 \%$ more likely to develop ON than patients treated with prednisone.

\section{CONCLUSION}

There have been several studies about the relationship between ALL prognosis and malnutrition. As it can be seen in this review, the results are quite diverse. There are many different methods for evaluating the nutritional status of the patients. The lack of a standardized method could be the reason of these contradictory results. The reason of the discrepancies between findings might also be due to the differences in sample sizes, cohort characteristics, and chemotherapeutic agents used in different studies. Larger trials examining appetite-regulating hormone levels and ALL disease progression are needed for better comparison. Therefore, it is not correct to compare every study. Nutritional status should still be considered, as ALL requires long-term treatment and has implications for both patients' quality of life and survival rates.

Adequate nourishment is crucial especially during the early treatment stages since inadequate nutrition could decrease the tolerance to chemotherapy as well as reduced immunity, and has negative effects on hematopoiesis $(22,47)$. It can lead to impaired production of blood cells, causing leucopenia and anemia. Furthermore, severe protein malnutrition in newborns and infants is related to atrophy in bone marrow and thymus, immature $T$ cell number in the periphery rises and CD4/CD8 ratio decreases (47). These effects of malnutrition can reduce the patient's immunity, which could make the patient more susceptible to infections affecting survival rate (47).

There is a growing understanding that malnutrition is complex and reflects a range of overlapping comorbidities that are not fully understood.

Patients with ALL have a high recovery rate even with chemotherapy alone, and these patients have a good chance of living a long, healthy life after treatment. Therefore, clinicians should be aware of the importance of nutritional status and focus on patients' quality of life during treatment.

\section{Ethics Committee Approval: N/A}

\section{Informed Consent: N/A}

Conflict of Interest: The authors declared no conflict of interest.

Author Contributions: Concept: E.C., I.K., E.Ç., C.Y., F.O.Ş., H.O.K., Design: E.C., I.K., E.Ç., C.Y., F.O.Ş., H.O.K., Supervision: E.C., I.K., E.Ç., C.Y., F.O.Ş., H.O.K., Resources: E.C., I.K., E.Ç., C.Y., F.O.Ş., H.O.K., Materials: E.C., I.K., E.Ç., C.Y., F.O.Ş., H.O.K., Data Collection and/ or Processing: E.C., I.K., E.Ç., C.Y., F.O.Ş., H.O.K., Analysis and/or Interpretation: E.C., I.K., E.Ç., C.Y., F.O.Ş., H.O.K., Literature Search: E.C., I.K., E.Ç., C.Y., F.O.Ş., H.O.K., Writing Manuscript: E.C., I.K., E.Ç., C.Y., F.O.Ş., H.O.K., Critical Review: E.C., I.K., E.Ç., C.Y., F.O.Ş., H.O.K.

Financial Disclosure: The authors declared that this study received no financial support.

\section{REFERENCES}

1. Khalid A. Evaluation of the nutritional status in children with acute lymphoblastic leukemia and its effect on the outcome of induction in a developing country. J Clin Oncol 2017;35:e22004. [Crossref]

2. Onciu M. Acute lymphoblastic leukemia. Hematol Oncol Clin North Am 2009;23:655-74. [Crossref] 
3. Terwilliger $T$, Abdul-Hay $M$. Acute lymphoblastic leukemia: a comprehensive review and 2017 update. Blood Cancer J 2017;7:e577. [Crossref]

4. Malard F, Mohty M. Acute lymphoblastic leukaemia. Lancet 2020;395:1146-62. [Crossref]

5. Barr RD, Gomez-Almaguer D, Jaime-Perez JC et al. Importance of Nutrition in the Treatment of Leukemia in Children and Adolescents. Arch Med Res 2016;47:585-92. [Crossref]

6. Bhutta ZA, Berkley JA, Bandsma RHJ et al. Severe childhood malnutrition. Nat Rev Dis Primers 2017;3:17067. [Crossref]

7. Cederholm T, Bosaeus I, Barazzoni R et al. Diagnostic criteria for malnutrition - An ESPEN Consensus Statement. Clin Nutr 2015;34:33540. [Crossref]

8. Kato M, Manabe A. Treatment and biology of pediatric acute lymphoblastic leukemia. Pediatr Int 2018;60:4-12. [Crossref]

9. Sala A, Pencharz P, Barr RD. Children, cancer, and nutrition--A dynamic triangle in review. Cancer 2004;100:677-87. [Crossref]

10. Mejía-Arangure JM, Fajardo-Gutíerrez $A$, Bernáldez-Ríos $R$ et al Nutritional state alterations in children with acute lymphoblastic leukemia during induction and consolidation of chemotherapy. Arch Med Res 1997;28:273-9. [Crossref]

11. Uderzo C, Rovelli A, Bonomi M et al. Nutritional status in untreated children with acute leukemia as compared with children without malignancy. J Pediatr Gastroenterol Nutr 1996;23:34-7. [Crossref]

12. Tazi I, Hidane Z, Zafad $S$ et al. Nutritional status at diagnosis of children with malignancies in Casablanca. Pediatr Blood Cancer 2008;51: 495-8. [Crossref]

13. Antillon F, de Maselli $T$, Garcia $T$ et al. Nutritional status of children during treatment for acute lymphoblastic leukemia in the Central American Pediatric Hematology Oncology Association (AHOPCA): preliminary data from Guatemala. Pediatr Blood Cancer 2008;50(2 Suppl):502-5; discussion 517. [Crossref]

14. Jaime-Pérez JC, González-Llano O, Herrera-Garza JL et al. Assessment of nutritional status in children with acute lymphoblastic leukemia in Northern México: A 5-year experience. Pediatr Blood Cancer 2008;50(2 Suppl):506-8; discussion 517. [Crossref]

15. Butturini AM, Dorey FJ, Lange BJ et al. Obesity and outcome in pediatric acute lymphoblastic leukemia. J Clin Oncol 2007;25:2063-9.[Crossref]

16. Lobato-Mendizábal E, Ruiz-Argüelles GJ, Marín-López A. Leukaemia and nutrition. I: Malnutrition is an adverse prognostic factor in the outcome of treatment of patients with standard-risk acute lymphoblastic leukaemia. Leuk Res 1989;13:899-906. [Crossref]

17. Gómez-Almaguer D, Ruiz-Argüelles GJ, Ponce-de-León S. Nutritional status and socio-economic conditions as prognostic factors in the outcome of therapy in childhood acute lymphoblastic leukemia. Int J Cancer Suppl 1998;11:52-5. [Crossref]

18. Tebeje NB, Bikes GA, Abebe SM et al. Prevalence and major contributors of child malnutrition in developing countries: systematic review and meta-analysis. J Child Obes 2017;2:16. [Crossref]

19. Fayh APT, Bezerra ADL, Friedman R. Appetite hormones in children and adolescents with cancer: a systematic review of observational studies. Nutr Hosp 2018;35:201-10. [Crossref]

20. Ladas EJ, Orjuela M, Stevenson K et al. Dietary intake and childhood leukemia: The Diet and Acute Lymphoblastic Leukemia Treatment (DALLT) cohort study. Nutrition 2016;32:1103-9.e1. [Crossref]
21. Gomes CC, Silva CCGD, Nascimento PRPD et al. Nutritional status and appetite-regulating hormones in early treatment of acute lymphoblastic leukemia among children and adolescents: a cohort study. Sao Paulo Med J 2020;138:118-25. [Crossref]

22. Brinksma A, Roodbol PF, Sulkers E et al. Weight and height in children newly diagnosed with cancer. Pediatr Blood Cancer 2015;62:26973. [Crossref]

23. Tan SY, Poh BK, Nadrah MH et al. Nutritional status and dietary intake of children with acute leukaemia during induction or consolidation chemotherapy. J Hum Nutr Diet 2013;26 Suppl 1:23-33. [Crossref]

24. Lindemulder SJ, Stork LC, Bostrom B et al. Survivors of standard risk acute lymphoblastic leukemia do not have increased risk for overweight and obesity compared to non-cancer peers: a report from the Children's Oncology Group. Pediatr Blood Cancer 2015;62:1035-41. [Crossref]

25. Park SH, Jung $M H$, Chung NG et al. Serum ghrelin and leptin concentrations in children with cancer: comparisons with normal children. Korean J Pediatr 2007;50:905-11. [Crossref]

26. Moschovi M, Trimis G, Vounatsou M et al. Serial plasma concentrations of adiponectin, leptin, and resistin during therapy in children with acute lymphoblastic leukemia. J Pediatr Hematol Oncol 2010;32:e813. [Crossref]

27. Esbenshade $A J$, Simmons $\mathrm{JH}$, Koyama $\mathrm{T}$ et al. Obesity and insulin resistance in pediatric acute lymphoblastic leukemia worsens during maintenance therapy. Pediatr Blood Cancer 2013;60:1287-91. [Crossref]

28. Green GJ, Weitzman SS, Pencharz PB. Resting energy expenditure in children newly diagnosed with stage IV neuroblastoma. Pediatr Res 2008;63:332-6. [Crossref]

29. Rickard KA, Foland BB, Detamore CM et al. Effectiveness of central parenteral nutrition versus peripheral parenteral nutrition plus enteral nutrition in reversing protein-energy malnutrition in children with advanced neuroblastoma and Wilms' tumor: a prospective randomized study. Am J Clin Nutr 1983;38:445-56. [Crossref]

30. Bakish J, Hargrave D, Tariq $N$ et al. Evaluation of dietetic intervention in children with medulloblastoma or supratentorial primitive neuroectodermal tumors. Cancer 2003;98:1014-20. [Crossref]

31. Mostoufi-Moab S, Halton J. Bone morbidity in childhood leukemia: epidemiology, mechanisms, diagnosis, and treatment. Curr Osteoporos Rep 2014;12:300-12. [Crossref]

32. Ward LM, Ma J, Lang B et al. Bone Morbidity and Recovery in Children With Acute Lymphoblastic Leukemia: Results of a Six-Year Prospective Cohort Study. J Bone Miner Res 2018;33:1435-43. [Crossref]

33. Inaba $\mathrm{H}, \mathrm{Cao} X, \mathrm{Han} \mathrm{AQ}$ et al. Bone mineral density in children with acute lymphoblastic leukemia. Cancer 2018;124:1025-35. [Crossref]

34. van der Sluis IM, van den Heuvel-Eibrink MM, Hählen K et al. Altered bone mineral density and body composition, and increased fracture risk in childhood acute lymphoblastic leukemia. J Pediatr 2002;141:204-10. [Crossref]

35. Cox CL, Zhu L, Kaste SC et al. Modifying bone mineral density, physical function, and quality of life in children with acute lymphoblastic leukemia. Pediatr Blood Cancer 2018;65:10.1002/pbc.26929. [Crossref]

36. Halton JM, Atkinson $S A$, Fraher $L$ et al. Altered mineral metabolism and bone mass in children during treatment for acute lymphoblastic leukemia. J Bone Miner Res 1996;11:1774-83. [Crossref]

37. Marinovic D, Dorgeret S, Lescoeur B et al. Improvement in bone mineral density and body composition in survivors of childhood 
acute lymphoblastic leukemia: a 1-year prospective study. Pediatrics 2005;116:e102-8. [Crossref]

38. Kunstreich $\mathrm{M}$, Kummer $\mathrm{S}$, Laws $\mathrm{HJ}$ et al. Osteonecrosis in children with acute lymphoblastic leukemia. Haematologica 2016;101:1295305. [Crossref]

39. Davies JH, Evans BA, Jenney ME et al. Skeletal morbidity in childhood acute lymphoblastic leukaemia. Clin Endocrinol (Oxf) 2005;63:1-9. [Crossref]

40. Alos N, Grant RM, Ramsay T et al. High incidence of vertebral fractures in children with acute lymphoblastic leukemia 12 months after the initiation of therapy. J Clin Oncol 2012;30:2760-7. [Crossref]

41. Kaste SC, Qi A, Smith K, et al. Calcium and cholecalciferol supplementation provides no added benefit to nutritional counseling to improve bone mineral density in survivors of childhood acute lymphoblastic leukemia (ALL). Pediatr Blood Cancer 2014;61:885-93. [Crossref]

42. Tylavsky FA, Smith K, Surprise $H$ et al. Nutritional intake of long-term survivors of childhood acute lymphoblastic leukemia: evidence for bone health interventional opportunities. Pediatr Blood Cancer 2010;55: 1362-9. [Crossref]

43. Girard $P$, Auquier $P$, Barlogis $V$ et al. Symptomatic osteonecrosis in childhood leukemia survivors: prevalence, risk factors and impact on quality of life in adulthood. Haematologica 2013;98:1089-97. [Crossref]

44. Mattano LA Jr, Sather HN, Trigg ME et al. Osteonecrosis as a complication of treating acute lymphoblastic leukemia in children: a report from the Children's Cancer Group. J Clin Oncol 2000;18:3262-72. [Crossref]

45. Aricò $M$, Boccalatte MF, Silvestri $D$ et al. Osteonecrosis: An emerging complication of intensive chemotherapy for childhood acute lymphoblastic leukemia. Haematologica 2003;88:747-53. [Crossref]

46. Kadan-Lottick NS, Dinu I, Wasilewski-Masker K et al. Osteonecrosis in adult survivors of childhood cancer: a report from the childhood cancer survivor study. J Clin Oncol $2008 ; 26: 3038-45$. [Crossref]

47. Getawa S, Getaneh Z, Melku M. Hematological Abnormalities and Associated Factors Among Undernourished Under-Five Children Attending University of Gondar Specialized Referral Hospital, Northwest Ethiopia. J Blood Med 2020;11:465-78. [Crossref] 